\title{
FORMAÇÃO DOCENTE EM EDUCAÇÃO FíSICA: PERSPECTIVAS DE UMA RACIONALIDADE PEDAGÓGICA DO CORPO EM MOVIMENTO
}

\author{
ABREU, Samara Moura Barreto de (Brasil, Ceará, Fortaleza) $)^{1 *}$ \\ SABÓIA, Wilson Nóbrega (Brasil, Ceará, Fortaleza) ${ }^{2 * *}$ \\ NOBREGA-THERRIEN, Silvia Maria (Brasil, Ceará, Fortaleza) ${ }^{1 * \star *}$ \\ ${ }^{1}$ Universidade Estadual do Ceará \\ 2Universidade de Fortaleza \\ ORCID ID: https://orcid.org/0000-0003-1198-5602* \\ ORCID ID: https://orcid.org/0000-0002-3246-2854 \\ ORCID ID: https://orcid.org/0000-0002-8412-8575*
}

\begin{abstract}
RESUMO
É tecido como objetivo deste trabalho discutir as clivagens histórico-críticas na formação docente em Educação Física como caminho que aponta perspectivas de uma racionalidade pedagógica do corpo em movimento. Constitui-se o escrito como ensaio teórico-reflexivo ancorado nos fundamentos do paradigma crítico da Educação Física significado pela práxis, na qual os (des)caminhos da formação e desenvolvimento profissional reverberam no pensamento reflexivo-crítico como modo de agir cultural e epistemologicamente. A leitura histórico-crítica da realidade na profissão docente em Educação Física aponta como emergente a (re)construção de traços identitários na Educação Física sobre o ser-fazer imperativo, em oposição às forças hegemônicas neoliberais, como significação das relações de empoderamento que encenam o palco das transformações didáticas, vislumbrando o processo de redemocratização das ideias pedagógicas.
\end{abstract}

\section{PALAVRAS-CHAVE}

Formação docente em Educação Física. Racionalidade pedagógica. Cultura corporal de movimento.

\section{TEACHER TRAINING IN PHYSICAL EDUCATION: PERSPECTIVES OF A PEDAGOGICAL RATIONALITY OF THE BODY IN MOTION}

\begin{abstract}
The purpose of this paper is to discuss the historical-critical divisions in teacher training in Physical Education, as a way that points out perspectives of a pedagogical rationality of the body in motion. It is written as a theoretical-reflexive essay anchored in the foundations of the Critical Paradigm of Physical Education meant by praxis, in which the (mis)leading directions of the professional formation and development reverberate in a reflexive-critical thinking, as a way of acting both culturally and epistemologically. The historical-critical reading of reality in the teaching profession in Physical Education points out as emergent the (re)construction of identity traits in Physical Education about the imperative to be-to do, as opposed to neoliberal hegemonic forces, as a signification of the empowering relations which compose the stage of didactic transformations, glimpsing the process of redemocratization of the pedagogical ideas.
\end{abstract}

\section{KEYWORDS}

Teacher training in Physical Education. Pedagogical rationality. Body movement culture. 


\title{
FORMACIÓN DOCENTE EN EDUCACIÓN FÍSICA: PERSPECTIVAS DE UNA
} RACIONALIDAD PEDAGÓGICA DEL CUERPO EN MOVIMIENTO

\begin{abstract}
RESUMEN
El objetivo de este trabajo es discutir las brechas histórico-críticas de la formación docente en Educación Física, como camino que apunta perspectivas para la reconstrucción de una racionalidad pedagógica del cuerpo en movimiento. Este trabajo se constituye como ensayo teórico-reflexivo anclado en los fundamentos del paradigma crítico de la Educación Física y expresado por la praxis, en la cual los caminos y (des)caminos en la formación y desarrollo profesional reverberan en el pensamiento crítico-reflexivo como una manera de actuar cultural y epistemológicamente. La lectura histórico-crítica de la realidad en la profesión docente en Educación Física apunta como emergente la (re)construcción de trazos de identidad sobre el ser-hacer imperativo en la Educación Física, en oposición a las fuerzas hegemónicas neoliberales como significado de las relaciones de empoderamiento que se ponen en el escenario de las transformaciones didácticas, vislumbrando el proceso de redemocratización de las ideas pedagógicas.
\end{abstract}

\section{PALABRAS CLAVE}

Formación docente en Educación Física. Racionalidad pedagógica. Cultura corporal del movimiento.

\section{1 À GUISA DE INTRODUÇÃO: ALGUMAS CONSIDERAÇÕES}

A história da educação brasileira e consequentemente da Educação Física nos convida a perceber os (des)caminhos da profissionalização docente, especialmente quando o foco aponta para a leitura do presente, que se enraíza no passado e se projeta no futuro, produzindo a consciência da historicidade humana (SAVIANI, 2007). Essa consciência interage com os elementos estruturais da vida política, econômica e social, a partir dos quais se formam historicamente relações, condições e valores que persistem como "elementos ativos" na produção da nossa formação e desenvolvimento profissional. Tais elementos são reverberados na cultura escolar, definindo os traços constitutivos centrais desta e, por conseguinte, os principais desafios para o pensamento e a ação comprometidos com sua transformação.

A formação docente em Educação Física é cerne das nossas discussões neste ensaio, subscrevendo as clivagens histórico-críticas em retroação reflexiva para pensar perspectivas reordenadoras de uma racionalidade pedagógica. Entendemos como clivagem os (in)vieses histórico-políticos que, realçados pelas forças políticas 
hegemônicas, fragmentaram o pensamento pedagógico da Educação Física em significação do seu construto identitário.

Demarcamos, portanto, o conceito de corpo alienado e corpo emancipado na leitura dessa realidade histórica, incutindo as (im)permeabilidades da construção identitária profissional e suas representações ontológicas e pedagógicas, cujas evidências apontam para a necessária transmutação de um ideário político de um conhecimento hegemônico. Tal conhecimento considera corpo alienado para o agir cultural de (re)ação política de uma racionalidade contra-hegemônica e corpo emancipado como dimensão de transformação social.

$\mathrm{Na}$ perspectiva de uma racionalidade eminentemente técnica na Educação Física, assumimos como corpo alienado a representação de um produto-objeto à disposição das forças hegemônicas e, logo, a uma cultura de alienação e acrítica da realidade objetiva. Essa realidade é destinada a:

[...] [a]prender a comportar-se, movimentar-se, ser preciso e ter ritmo. Gestos são fabricados e sentimentos são produzidos. Este adestramento é resultado da aplicação de técnicas positivas de sujeição baseadas em saberes pedagógicos, médicos, sociológicos, físicos etc. O corpo torna-se útil e eficiente, mas ao mesmo tempo torna-se dócil e submisso: o corpo só se torna força útil se é ao mesmo tempo corpo produtivo e corpo submisso. (FOUCAULT, 1977, p. 28).

Nesse contexto, o corpo é reduzido a um objeto ou "máquina", ativado por uma razão centralizadora, como um ditame do "tecnicismo". Para tanto, reforçam-se as ideias pedagógicas de modo arbitrário para a consolidação do ensino, tomando como preceitos a "domesticalização" ou "docilidade" dos corpos humanos, de modo a garantir os direitos privados e públicos, refutando os que não se subjugam à ordem estabelecida (VARGAS; MOREIRA, 2012), uma vez que:

[...] a organização, a mobilização e a canalização dos desejos humanos, o envolvimento político ativo com táticas de persuasão, vigilância e coerção tornam-se parte do aparato de consumo do capitalista, produzindo, por sua vez, todo tipo de pressões sobre o corpo como sede do 'consumo racional', bem como seu agente performativo, para fins de maior acumulação. (HARVEY, 2010, p. 153).

De outro modo, em convergência com a racionalidade pedagógica, afirmamos que o corpo emancipado é representado como um construto sujeito à disposição de 
(re)ação contra-hegemônica e situado pela emancipação cultural e pensamento crítico. Em relação a isso, Freire (1978, p. 65) considera:

[...] que mulheres e homens estão não apenas no mundo, mas com o mundo. Somente homens e mulheres, como seres 'abertos', são capazes de realizar a complexa operação de, simultaneamente, transformando o mundo através de sua ação, captar a realidade e expressá-la por meio da linguagem criadora. E é enquanto são capazes de tal operação, que implica em 'tomar distância' do mundo, objetivando-o, que homens e mulheres se fazem seres como o mundo.

Assim, aferimos que "[...] o corpo também está diretamente mergulhado num campo político; as relações de poder têm alcance imediato sobre ele; elas o investem, o marcam, o dirigem, o supliciam, sujeitam-no a trabalhos, obrigam-no a cerimônias, exigem-lhes sinais" (FOUCAULT, 1977, p. 28).

Como modo de um agir cultural prospectivo de uma racionalidade pedagógica da cultura corporal do movimento, fomentamos a educação dos corpos na perspectiva de uma ação libertadora, justificando a disposição reflexiva deste ensaio com a posição de Arroyo (2000, p. 72), quem entende que:

[...] a educação dos corpos - não o seu adestramento e controle merece maior atenção nos processos escolares. É uma das lacunas mais lamentáveis em nossa pedagogia. Recolocar o corpo na centralidade que ele tem na construção de nossa identidade e da totalidade da nossa cultura exige criatividade profissional de todos.

Conforme anuncia Bracht (1999, p. 71), o "[...] papel da corporeidade na aprendizagem foi historicamente invisibilizado e negligenciado [...]. O déficit de dignidade do corpo vinha de seu caráter secundário perante a força emancipatória do espírito ou da razão". Assim, o sentido de valoração do corpo não se relacionava com as pretensões da racionalidade, uma vez que "[...] os princípios que fundamentaram essa valorização, ou seja, o privilégio concedido à razão, no entanto, encontram-se hoje amplamente desestabilizados" (VARGAS; MOREIRA, 2012, p. 411). Nesse contexto, demarcamos hibridamente a crise da racionalidade e a crise da modernidade, cuja realidade entoa sobre a capilaridade justaposta entre a crise da racionalidade e a crise da modernidade.

Portanto, essa crise aponta uma ressignificação na formação e desenvolvimento profissional docente como mudança paradigmática numa concepção reflexivo-crítica. Concordamos com Fensterseifer (2006), ao referir-se à ideia de uma práxis da cultura 
corporal do movimento como ação de devolver os corpos, em permanente transformação, ao mundo, como espaços de liberdade humana. Isso implica, pois, a compreensão do corpo diante da realidade social, da educação e da política composta no interior de uma cultura, do corpo envolto das dimensões ética e estética pela intersubjetividade e dialogicidade.

Nesse sentido, como objetivo deste artigo, propomos discutir as clivagens histórico-críticas na formação docente em Educação Física como caminho que aponta perspectivas de uma racionalidade pedagógica do corpo em movimento.

\section{O IDEÁRIO POLÍTICO DE UMA RACIONALIDADE HEGEMÔNICA - O CORPO ALIENADO}

Em berços militares, foi constituída a história da nossa formação profissional como professores de Educação Física. As escolas de formação têm origem nas primeiras décadas do século $X X$ e tinham o intuito prioritariamente de formar militares (BENITES; SOUZA NETO; HUNGER, 2008). Avistávamos nesse solo a influência de métodos ginásticos como meio de formar um corpo heroico a serviço da nossa "pátria amada, mãe gentil". Essa essência emergente de formação corporal é revigorada nos ambientes escolares, assumindo lugar prestigiado nas aulas de Educação Física.

Enaltecemos que em 1851 as aulas de Educação Física foram introduzidas nas escolas brasileiras e que em 1854 a ginástica se tornou disciplina obrigatória nas aulas de Educação Física no ensino primário. Era preciso formar mão de obra para atender a esse fim, de caráter eminentemente político e insipidamente pedagógico. Essa mão de obra foi intitulada "professores", o que significava ou tinha o mesmo sentido de adestradores/instrutores. "As funções atribuídas ao instrutor eram as de apresentar os exercícios, dirigir, manter a ordem e a disciplina. Nessa relação de instrução ao aluno, cabia competir, repetir e cumprir a tarefa atribuída pelo instrutor" (BRACHT, 1989, p. 14). "Um, dois, três, quatro... Um, dois, três, quatro...", isso era o que ecoava repetidamente nas aulas de Educação Física, compondo um movimento de "ação" sem dedicar-se à "reflexividade".

A reflexividade é aqui entendida por nós como um processo de autoconsciência sobre um ato de curiosidade epistemológica, o que permite a superação do saber 
ingênuo, do senso comum, indo em direção ao "pensar certo". "Pensar certo implica a existência de sujeitos que pensam mediados por objeto ou objetos sobre o que incide o próprio pensar dos sujeitos" (FREIRE, 1996, p. 21).

Nas palavras de Freire (1996, p. 17), essa superação do saber ingênuo para o saber epistêmico se dá "[...] na medida em que a curiosidade ingênua, sem deixar de ser curiosidade, se criticiza. Ao criticizar-se, tornando-se, então, [...] curiosidade epistemológica, metodicamente 'rigorizando-se' na sua aproximação ao objeto".

O processo de militarização na Educação Física brasileira sustentava o trato do conhecimento sobre o saber-fazer, arquitetado eminentemente na prática, portanto uma fragilidade no trato do conhecimento sobre o campo teórico. Nesse sentido, os militares revestiram-se de professores de Educação Física até que fossem criados espaços de formação para os civis, como o Curso Provisório de Educação Física, em 1929, ministrado pelo exército, pioneiro no acolhimento aos civis (AZEVEDO; MALINA, 2004).

$\mathrm{Na}$ década de 1930, esse curso se revelou como importante no âmbito da universalização da formação em Educação Física, acolhendo a sociedade civil. Vemos a criação da Escola de Educação Física do Exército (EsEFEx) no Rio de Janeiro, em 1933, a partir do Decreto-Lei de n. 23.232, da Escola de Educação Física de São Paulo, em 1934, e da Escola Nacional de Educação Física e Desporto (ENEFD), na Universidade do Brasil, em 1939. A ENEFD foi criada pelo Decreto-Lei n. 1.212, e seus cursos abrangiam territorialmente os estados do Espírito Santo, Pará, Pernambuco e São Paulo, não gozando de regulamentação e pautados em modelos militares (AZEVEDO; MALINA, 2004).

Os egressos do curso normal foram convidados a obter "[...] uma formação de normalista no âmbito da Educação Física; de instrutor no curso de Massagista; de Técnico Desportivo ou de médico especializado em Educação Física; e de professor de Educação Física, que era obtido em dois anos de formação" (BENITES; SOUZA NETO; HUNGER, 2008, p. 346), sendo a única licenciatura ofertada na ENEFD com essa duração, visto que as outras eram de três anos.

Além da forte influência militarista na formação de professores de Educação Física, evidenciamos a existência, nesse período, da hegemonia/dominação da classe médica sobre os (des)caminhos dessa formação aliada às forças políticas para a manutenção de uma ordem social e econômica em ascensão, a qual, por sua vez, tinha 
como um dos princípios a eugenia. Aos médicos convinha restritamente o ensino das aulas teóricas, de caráter biologicista. As aulas práticas eram ministradas por destacados esportistas, não havendo exigência de nível superior para o ensino na ENEFD. Assim, resplandece na Educação Física a formação na perspectiva técnico-biológica (AZEVEDO; MALINA, 2004).

É conveniente assinalarmos que nessa perspectiva não havia lugar para a afirmação das disciplinas pedagógicas, e a dimensão dos conteúdos pautava-se sobre o "saber-fazer", sem atenção para o "saber" e o "saber ser", como saber situado, contextualizado. A didática era um apêndice na formação profissional, cuja relação entre teoria e prática era distanciada.

Dessa forma, o domínio da teoria era desligado das práticas sociais, (SACRISTÁN, 1999), apontando para um descaminho de uma racionalidade crítica e pedagógica. "A conclusão sobre esse processo era a de que os profissionais que saíam formados pelo curso da ENEFD eram estritamente técnicos, desprovidos de fundamentação teórica consistente" (AZEVEDO; MALINA, 2004, p. 132).

Alterações na formação de professores de Educação Física ocorreram com a reforma política instaurada com o fim do Estado Novo. Nessa época, destacaram-se a equivalência da relação temporal (três anos) aos outros cursos de licenciatura (Decreto-Lei n. 8.270/1945) e posteriormente a obrigatoriedade do $2^{\circ}$ ciclo (ensino médio) para ingresso dos professores formadores (Decreto n. 1.921/1953), ainda que tenha deixado de ser um curso técnico somente em 1957 (BENITES; SOUZA NETO; HUNGER, 2008).

Apesar de mudanças e reformas consideradas importantes, não se observou transformação do pensamento político sobre a formação de Educação Física, ainda carente de bases teóricas fundantes, capazes de alcançar uma perspectiva crítica. Isso se tornou evidente com a assunção do "fazer pelo fazer", sustentada pela racionalidade técnica no período pós-guerra e fomentada pela orientação/tendência tecnicista que permeou fortemente a educação brasileira nas décadas de 1960 e 1970, sob a égide da ditadura militar.

A racionalidade técnica ligada à perspectiva tecnicista incute a prevalente busca pela "[...] produtividade guiada pelo princípio de racionalidade, que se traduz no empenho em se atingir o máximo de resultados com o mínimo de dispêndio" (SAVIANI, 2002, p. 23). Sobre a orientação tecnicista, Bracht (1989, p. 15) destaca que prevalecem os: 
[...] objetivos operacionais, do planejamento, da tecnologia do ensino. Menos o professor e o aluno, têm importância o processo de ensino, e mais o planejamento. Sob esta orientação ocorreram reducionismos, ou uma segunda redução do movimento corporal nas aulas de Educação Física (a primeira redução já havia ocorrido através da assimilação do código do desporto), pela necessidade de operacionalizar os objetivos, o que levou, pelo menos na tendência, à substituição do lúdico em favor de tarefas mecânicas.

No contexto do golpe militar, assistimos à Educação Física se distanciar de um processo de autonomia pedagógica e se colocar refém da sinuosa política de "pão e circo". Com isso, ocorreu o fortalecimento da formação técnico-desportiva e da consequente revitalização da imagem do professor de Educação Física como técnico ou treinador. Como tal, o ensino que ministrava pautava-se na mecanização de gestos técnicos, expressando o caráter instrumental. Sobre esse momento da racionalidade técnica demasiada, Castellani Filho (1988, p. 107) expressa:

Teve ela (Educação Física) - dada a contundente presença da visão tecnicista nas Leis n. 5.540/68 e 5.692/71 - reforçando o seu caráter instrumental, caráter esse que, num primeiro instante, veio a configurar-se no zelar, enfaticamente, pela preparação, recuperação e manutenção da força de trabalho, buscando, com esse proceder, assegurar ao ímpeto desenvolvimentista então em voga mão de obra fisicamente adestrada e capacitada. Esse caráter instrumental evidencia-se ainda mais quando o Decreto n. 69.450/71, em seu artigo $1^{\circ}$, refere-se a ela como sendo '[...] atividade que, por seus meios, processos e técnicas, desperta, desenvolve e aprimora forças físicas, morais, cívicas, psíquicas e sociais do educando, constituindo-se em um dos fatores básicos para a conquista das finalidades da Educação Nacional'.

Nessa temporalidade, o esporte se tornou objeto ideológico a partir do fenômeno da "espetacularização", cuja finalidade era silenciar e arregimentar forças oponentes aos movimentos sociais, em especial o movimento estudantil com vistas à reforma universitária.

Tais representações hegemônicas polarizadas na constituição histórica da Educação Física, do início da década de 1930 à década de 1980, assumiram sobremaneira uma racionalidade do corpo alienado às forças produtivas hegemonicamente ascendentes, implicadas pelo capital. Este "[...] se empenha continuamente em moldar os corpos de acordo com seus próprios requisitos, ao mesmo tempo que internaliza em seu modus operandi efeitos de desejos corporais, vontades, 
necessidades e relações sociais em mudança e interminavelmente inacabados" (HARVEY, 2000, p. 157).

\section{O RE(AGIR) POLÍTICO DE UMA RACIONALIDADE CONTRA-HEGEMÔNICA - O CORPO EMANCIPADO?}

Como movimento de re(ação), apenas na década 1980 se começou a cultivar um movimento político pela (re)significação da área da Educação Física, o que inclui a busca de sua identidade, do seu objeto epistêmico e de sua legitimação social. O ensejo era de superação do modelo técnico-instrumental na formação e prática docente, movida pelas experiências pedagógicas encetadas pelas pedagogias críticas sobre o chão da escola, lócus de investigação e territorialização da Educação Física nessa realidade temporal.

No mesmo período, no campo da formação de professores, a vigência do parecer CFE 215 incidiu na conversão de dois tipos de modelos de formação: o tradicional-desportivo, estruturado nas práticas esportivas; e o técnico-científico, prevalecendo à fundamentação de um corpo de conhecimento (BETTI; RANGEL-BETTI, 1996).

Tal dualidade tangenciou a distinção das áreas de conhecimento na Educação Física: conhecimento do ser humano; da sociedade; filosófico; e técnico. Devido a isso, as estruturas curriculares dos cursos de graduação modelaram-se sob as perspectivas humanística e tecnicista, como vertentes educativas paradigmáticas. Embora estreitando laços com as Ciências Sociais e Humanas, as Ciências Naturais com viés positivista ainda prevaleciam sobre o cientificismo, fundando as práticas pedagógicas. Para Bracht (1999, p. 77):

[...] [e]ra preciso orientar a prática pedagógica com base no conhecimento científico, este, por sua vez, entendido como aquele produzido pelas ciências naturais ou com base em seu modelo de cientificidade. $O$ desconhecimento da história da EF [Educação Física] fez com que não se percebesse que esse movimento apenas atualizava o percurso e a origem histórica da EF e, portanto, que ele não rompia com o próprio paradigma da aptidão física.

Nesse contexto, o pensamento pedagógico e científico na Educação Física reverberava sobre as ideias desenvolvimentistas, que não levavam a uma realidade pedagógica histórico-cultural sobre o movimento de autonomia e emancipação social 
como verdadeiro processo de redemocratização e de reflexividade numa relação intersubjetiva. Considerava-se que:

[...] reflexibilidade não supõe conceber alguns indivíduos deixados à mercê de suas próprias invenções, mas a sua consideração como sujeitos que se tornaram nexos nos quais são cruzadas as elaborações culturais públicas, como as ciências - os significados intersubjetivos próprios da ação social compartilhados e as construções. Ou seja, não podemos separar os processos reflexivos individuais dos processos de comunicação de significados entre as elaborações subjetivas e as culturais. (SACRISTÁN, 1999, p. 101).

Importantes movimentos em torno das políticas educacionais e da cientifização foram assistidos na década de 1980, cujo destaque vai para o nascimento de algumas entidades: a Associação Nacional de Educação (ANDE), a Associação Nacional de Pós-Graduação e Pesquisa em Educação (ANPEd), o Centro de Estudos Educação e Sociedade (Cedes) e a Confederação de Professores do Brasil (CPB), transformada na Confederação Nacional dos Trabalhadores da Educação (CNTE) (SAVIANI, 2007).

No âmbito da Educação Física, ainda no mesmo período, surgiram os primeiros grupos de pesquisa derivados da ascensão da formação de mestres e doutores na área, possibilitando a constituição dos primeiros cursos de mestrado em Educação Física nas regiões Sul e Sudeste, dando início à "elite intelectual" responsável pela Educação Física brasileira (SILVA, 1997). "O primeiro grupo de pesquisa surgiu na universidade de Porto Alegre (UFRGS/RS) em 1986 e, em anos subsequentes, surgiu um grupo na PUC/SP (1987), um na USP e dois na Unicamp (1988)" (DUCA et al., 2011, p. 609). Ressaltamos que apenas a Pontifícia Universidade Católica de São Paulo (PUC/SP) não possuía programa de pós-graduação em Educação Física.

O conhecimento epistêmico brotava no campo da Educação Física, mas não fundamentalmente vinculado a uma perspectiva crítica de educação, cuja aproximação se faz, ainda que em processo de maturação, ao movimento progressista da Educação Física, estreitado à pedagogia crítica superadora e crítica emancipatória no início da década de 1990. Nessa temporalidade, urge, portanto, a necessária ressignificação identitária da Educação Física, o que inclui, segundo Bracht (1999, p. 81):

[...] entender o objeto da EF, o movimentar-se humano, não mais como algo biológico, mecânico ou mesmo apenas na sua dimensão psicológica, e sim como fenômeno histórico-cultural. Portanto, essa leitura ou esse

Educação \& Formação, Fortaleza, v. 4, n. 12, p. 191-206 set./out. 2019

DOI: https://doi.org/10.25053/redufor.v4i12.897 
entendimento da Educação Física só criará corpo quando as ciências sociais e humanas forem tomadas mais intensamente como referência. No entanto, é preciso ter claro que a própria utilização de um novo referencial para entender o movimento humano está na dependência da mudança do imaginário social sobre o corpo e as atividades corporais.

Ainda destacamos na década de 1990 mudanças nas políticas nacionais de formação de professores, com a aprovação da Lei de Diretrizes e Bases da Educação Nacional, em 1996, Lei n. 9.394. Tal lei opera sob o ideário de uma formação docente como continuum estreitado ao desenvolvimento profissional, cuja prerrogativa estabelece uma aproximação com a práxis pedagógica.

Embora reconheçamos as transformações ocorridas no final do século $X X$ no cenário educativo brasileiro como movimento de superação da racionalidade técnica, no contexto da Educação Física essas evidências caminham a passos mais lentos. Ainda reverbera, neste século XXI, o ensejo de (re)conhecer o objeto da Educação Física na contextualidade das políticas educacionais, visto que ainda se vincula o pensamento sobre esta a uma prática hegemônica eminentemente técnica. Essa tendência limita os espaços de formação reflexiva diante da experiência vivida nos cenários educativos, cuja realidade ainda aponta para a desprofissionalização do professor nessa área, mercantilização esportiva e despolitização identitária em torno de evidências de modelos reprodutivistas no âmbito da formação docente.

Nesse sentido, avistamos a confluência de diversos tipos de racionalidades sobre o domínio científico e pedagógico da área, sobremaneira a racionalidade técnica. Conforme elucidam Alves e Carvalho (2015, p. 8-9):

[...] [a] pesquisa imersa no plano da experiência é, certamente, uma prática investigativa estranha à Educação Física, haja vista a evidente afinidade da área com as metodologias científicas tradicionais pautadas pela visão positiva de ciência. A intervenção profissional endossa o peso desta afinidade quando se preocupa muito mais com as regularidades e prescrições que mediam a relação profissional-sujeito do que com os processos que movem esta relação para além desta restrita visão pedagógica e didática que suporta e que reconhece como devida. A visão tecnicista se instala como exigência objetiva na busca de uma evidência, ou melhor, de uma exatidão sobre o objeto verificado (no caso do pesquisador) e sobre a intervenção proposta (no caso da atuação profissional e docente). E esta instalação está fortemente fixada nos conceitos e nas representações justamente para não se escapar dela. Em função desta perspectiva imperativa, que de tão corrente tornou-se quase natural, o foco do olhar é orientado mediante uma realidade forjada na 
objetividade, pois, sem ela, não é possível sistematizar um conhecimento

e tampouco aplicá-lo na prática profissional e docente.

Como desafio, ainda operamos na perspectiva de uma "intelectualização" que caminhe sobre uma prática educativa contextualizada com a realidade sócio-histórica e sistematizada pela ação didático-pedagógica que aponte para uma emancipação dos atores sociais, conforme alude Demo (1994, p. 12), quando pontua que:

\begin{abstract}
Em termos de cidadania emancipatória, definida como a construção competente da autonomia do sujeito histórico, o instrumento primordial é manejo e produção de conhecimento. Assim, se educação pretende, de fato, ser equalizadora de oportunidades, abrir para os marginalizados chances reais de desenvolvimento, colocar nas mãos dos excluídos armas efetivas de luta, precisa aproximar-se, da melhor maneira possível, da construção de conhecimento.
\end{abstract}

Insistimos, portanto, numa mudança paradigmática pautada numa reflexividade que esteja estreitada a uma dimensão político-pedagógica que incida em medidas efetivas para a elevação da profissionalidade docente, com a intencionalidade de construir a identidade do professor como intelectual crítico e reflexivo (PIMENTA, 2005), diante de uma racionalidade pedagógica (THERRIEN, 2006). Esta, no contexto em questão, é significada como emancipação humana, imbuída de intersubjetividade em ato colaborativo, dialógico, em convergência de sentidos e significados, enfim, da sociabilidade da cultura corporal em movimento.

\title{
4 AGIR CULTURAL NA PERSPECTIVA DE UMA RACIONALIDADE PEDAGÓGICA DO CORPO EM MOVIMENTO: FINALIZANDO AS REFLEXÕES
}

A leitura histórico-crítica da realidade indica como emergente a (re)construção de traços identitários na formação e desenvolvimento profissional docente em Educação Física sobre o ser-fazer em torno de um agir cultural, em oposição às forças hegemônicas neoliberais, como significação das relações de empoderamento que encenam o palco das transformações didático-pedagógicas.

Vislumbramos, assim, o processo de redemocratização das ideias pedagógicas sobre uma racionalidade pedagógica do corpo em movimento na formação docente, a 
fim de incidir sobre uma escola reflexiva, ancorada no paradigma crítico como transformação da realidade social.

Desse modo, faz-se necessário um agir cultural subversivo, devendo ser a cultura do movimento uma práxis de libertação na formação do ser social em humanização. O sentido conferido à cultura do movimento é, portanto, fundado na determinação do contexto histórico-cultural (BRACHT, 1992).

Nesse sentido, conforme elucidam Bracht (1999) e Vargas e Moreira (2012), a busca por uma nova racionalidade da Educação Física impõe-se à mudança do imaginário social sobre o corpo e sua práxis, em tônica de superação da dicotomia mente/corpo e sujeito/objeto como referente de processos de autonomização e autorização docente.

Tal práxis é anunciada como ressignificação do trabalho que consiste em formação e desenvolvimento profissional docente. A valorização desse profissional não se opera de modo secundarizado em relação ao trabalho material, mas sim como uma premissa para a transformação das sociedades contemporâneas (TARDIF; LESSARD, 2005), visando a um trabalho autônomo, criativo e crítico, numa reexistência democrática.

Evidentemente não a assim chamada modelagem de pessoas, porque não temos o direito de modelar as pessoas a partir do seu exterior; mas também não a mera transmissão de conhecimentos, cuja característica de coisa morta já foi mais do que destacada, mas a produção de uma consciência verdadeira. Isto seria inclusive da maior importância política; sua ideia [de H. Becker - NV], se é permitido dizer assim, é uma exigência política. Isto é: uma democracia com o dever de não apenas funcionar; mas operar conforme seu conceito, demanda pessoas emancipadas. Uma democracia efetiva só pode ser imaginada enquanto uma sociedade de quem é emancipado. (ADORNO, 1995, p. 141-142).

Por fim, evidenciamos que tal historicidade da Educação Física, revisitada com a âncora fincada em estudiosos preocupados com essas questões também epistêmicas, ajudou-nos a compreender as reverberações do contexto histórico-social na construção do objeto epistemológico da Educação Física. Foi possível reconhecer seus desafios e apontar para possíveis mudanças, entendendo que "[...] a transformação é possível porque a consciência não é um espelho da realidade, simples reflexo, mas é reflexiva e refletora da realidade" (FREIRE; SHOR, 2011, p. 33, grifo dos autores). 
Portanto, que sejam empreendidos esforços imperativos para essa transformação social, tomando uma visão crítico-dialética em face da relação educação/sociedade, que dimensione espaço para a atuação transformadora da práxis no campo dessa formação e profissão. Para tanto, anunciamos como assunções necessárias de uma racionalidade pedagógica na formação docente em Educação Física:

1. A cultura do corpo em movimento em ato de resistência: impelida segundo a compreensão e (re)ação sobre os dilemas emergentes da práxis pedagógica na relação entre o instituído (a racionalidade objetiva/macropolítica verticalidade) e o instituinte (a racionalidade subjetiva/micropolítica horizontalidade), em contexto de uma epistemologia da práxis como empoderamento docente;

2. A cultura do corpo em movimento em ato de reexistência: mobilizada pela ontologia do "ser mais" em sustentabilidade da dialogicidade pelos atores/autores curricularizantes (atos de currículo), nas enunciações culturais de uma práxis educativa transgressora pela produção de sentidos coletivos na descolonização de uma racionalidade eminentemente técnica.

\section{REFERÊNCIAS}

ADORNO, T. W. Educação e emancipação. Rio de Janeiro: Paz e Terra, 1995.

ALVES, F. S.; CARVALHO, Y. M. A Educação Física no plano da experiência: implicações na pesquisa e na intervenção profissional e docente. Pensar a Prática, Goiânia, v. 18, n. 1, p. 1-12, 2015.

ARROYO, M. Ofício de mestre: imagens e autoimagens. Petrópolis: Vozes, 2000.

AZEVEDO, Â. C. B.; MALINA, A. Memória do currículo de formação profissional em Educação Física no Brasil. Revista Brasileira de Ciências e Esportes, Campinas, v. 25, n. 2, p. 129-142, 2004.

BENITES, L. C.; SOUZA NETO, S.; HUNGER, D. A. C. F. O processo de constituição histórica das diretrizes curriculares na formação de professores de Educação Física. Educação e Pesquisa, São Paulo, v. 34, p. 343-360, 2008.

BETTI, M.; RANGEL-BETTI, I. C. A. R. Novas perspectivas na formação profissional em Educação Física. Revista Motriz, Rio Claro, v. 2, n. 1, p. 10-15, 1996. 
BRACHT, V. A constituição das teorias pedagógicas da Educação Física. Cadernos Cedes, Campinas, v. 19, n. 48, p. 69-88, 1999.

BRACHT, V. Educação Física: a busca da autonomia pedagógica. Revista da Fundação de Esporte e Turismo, Curitiba, v. 1, n. 2, p. 12-19, 1989.

BRACHT, V. Educação Física e aprendizagem social. Porto Alegre: Magister, 1992.

BRASIL. Lei n. 9.394, de 20 de dezembro de 1996. Estabelece as Diretrizes e Bases da Educação Nacional. Diário Oficial [da] República Federativa do Brasil, Poder Executivo, Brasília, DF, 21 dez. 1996.

CASTELLANI FILHO, L. Educação Física no Brasil: a história que não se conta. Campinas: Papirus, 1988.

DEMO, P. Pesquisa e construção de conhecimento: metodologia científica no caminho de Habermas. Rio de Janeiro: Tempo Brasileiro, 1994.

DUCA, G. F. et al. Grupos de pesquisa em cursos de Educação Física com pós-graduação "stricto sensu" no Brasil: análise temporal de 2000 a 2008. Revista Brasileira de Educação Física e Esporte, São Paulo, v. 25, n. 4, p. 607-617, 2011.

FENSTERSEIFER, P. E. Corporeidade e formação do profissional na área da Saúde. Revista Brasileira de Ciências do Esporte, Campinas, v. 27, n. 3, p. 93-102, 2006.

FOUCAULT, M. Vigiar e punir: nascimento da prisão. Petrópolis: Vozes, 1977.

FREIRE, P. A ação cultural para a liberdade e outros escritos. Rio de Janeiro: Paz e Terra, 1978.

FREIRE, P. Pedagogia da autonomia: saberes necessários à prática educativa. São Paulo: Paz e Terra, 1996.

FREIRE, P.; SHOR, I. Medo e ousadia: o cotidiano do professor. 13. ed. Rio de Janeiro: Paz e Terra, 2011.

HARVEY, D. O corpo como estratégia de acumulação. In: HARVEY, D. Espaços de esperança. São Paulo: Loyola, 2000. p. 135-160.

PIMENTA, S. G. Docência no ensino superior. 2. ed. São Paulo: Cortez, 2005.

SACRISTÁN, J. G. Poderes instáveis em educação. Porto Alegre: Artes Médicas, 1999.

SAVIANI, D. História das ideias pedagógicas no Brasil. Campinas: Autores Associados, 2007. 
SAVIANI, D. Transformações do capitalismo, do mundo do trabalho e da educação. In: LOMBARDI, J. C., SAVIANI, D.; SANFELICE, J. L. (Org.). Capitalismo, trabalho e educação. Campinas: Autores Associados, 2002. p. 13-24.

SILVA, R. V. S. Pesquisa em Educação Física: determinações históricas e implicações epistemológicas. 1997. 279 f. Tese (Doutorado em Educação) - Programa de Pós-Graduação em Educação, Universidade de Campinas, Campinas, 1997.

TARDIF, M.; LESSARD, C. O trabalho docente: elementos para uma teoria da docência como profissão de interações humanas. Petrópolis: Vozes, 2005.

THERRIEN, J. Os saberes da racionalidade pedagógica na sociedade contemporânea. Revista Educativa, Goiânia, v. 9, n. 1, p. 67-81, 2006.

VARGAS, C. P.; MOREIRA, A. F. B. A crise epistemológica na Educação Física: implicações no trabalho docente. Caderno de Pesquisa, São Paulo, v. 42, n. 146, p. 408427, 2012.

\section{Samara Moura Barreto de Abreu (Brasil, Ceará, Fortaleza)}

Universidade Estadual do Ceará (UECE)

Mestra em Educação pela UECE. Coordenadora de área do Programa Institucional de Bolsas de Iniciação à Docência (Pibid) Educação Física do Instituto Federal de Educação, Ciência e Tecnologia (IFCE), campus Canindé.

Lattes: <http://lattes.cnpq.br/8989448843028647>.

E-mail: <samaraef@hotmail.com>.

\section{Wilson Nóbrega Sabóia (Brasil, Ceará, Fortaleza)} Universidade de Fortaleza (Unifor)

Mestre em Educação pela UECE. Técnico de equipe da Unifor.

Lattes: <http://lattes.cnpq.br/8882997671270844>.

E-mail: <wnsaboia@unifor.br>.

Silvia Maria Nobrega-Therrien (Brasil, Ceará, Fortaleza)

Universidade Estadual do Ceará (UECE)

Doutora em Sociologia em Educação pela Universidade de Salamanca, Espanha. Coordenadora do Laboratório de Educação e Saúde da UECE.

Lattes: <http://lattes.cnpq.br/8260706446079117>.

E-mail: <silnth@terra.com.br>.

Recebido em 03 de janeiro de 2018.

Aceito em 14 de outubro de 2018.

Educação \& Formação, Fortaleza, v. 4, n. 12, p. 191-206 set./out. 2019

DOI: https://doi.org/10.25053/redufor.v4i12.897

http://seer.uece.br/redufor 